\title{
Assessing the efficacy of novel oral anticoagulants after acute coronary syndrome
}

Hamza Mohamed Qabil, Ahmed Mohamed Ramzy, Mahmoud Shawky Abdelmoneum and Khedr Ahmed Abd Elfattah*

*Correspondence: khedrahmed0@gmail.com

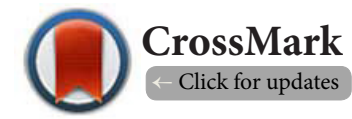

Department of Cardiology, Faculty of Medicine, Benha University, Egypt.

\begin{abstract}
Background: After an acute coronary syndrome(ACS), patients continue to be at risk of major adverse cardiovascular events (MACE) despite the standard treatment. The risk of MACE may be secondary to thrombin, which remains elevated after ACS.We evaluated the safety and efficacy of the novel oral anticoagulant (NOAC), factor Xa inhibitor rivaroxaban.

Methods: In our study, we randomly assigned 100 patients with a recent ACS to receive the once-daily dose of $2.5 \mathrm{mg}$ of rivaroxaban or placebo in addition to dual antiplatelet therapy for six months. The primary efficacy endpoint was a composite of death from cardiovascular events, myocardial infarction, and stroke, the secondary endpoint was death from cardiovascular events, myocardial infarction, or stroke with assessing the safety (risk of bleeding).

Results: Rivaroxaban significantly reduced the primary efficacy endpoint, as compared with placebo, with respective rates of $4 \%$ and $22 \%(\mathrm{P}=0.007)$. Regarding secondary endpoint, the $2.5 \mathrm{mg}$ dose of rivaroxaban reduced the rates of death from cardiovascular causes $(0 \%$ versus $8 \%, \mathrm{P}=0.041)$. As compared with placebo, rivaroxaban increased the rates of minor bleeding ( $12 \%$ vs. $2 \%, \mathrm{P}=0.049)$, with no major or fatal bleeding had been recorded.
\end{abstract}

Conclusion: In patients with a recent acute coronary syndrome, rivaroxaban reduced the risk of the composite endpoint of death from cardiovascular causes, myocardial infarction, or stroke. Rivaroxaban increased the risk of minor bleeding but not the risk of major or fatal bleeding.

Keywords: Acute coronary syndrome, novel oral anticoagulants, rivaroxaban

\section{Introduction}

Acute coronary syndrome (ACS) continues to be associated with significant morbidity and mortality [1], and major adverse cardiovascular events (MACEs) occur to the highest rates of the initial hospitalization and first 30 days after an ACS, this risk may be linked in part to the generation of thrombin which plays a major role in thrombus formation and platelet [2].

The MACE outcome can be defined as the composite of allcause mortality, myocardial infarction, or stroke.Myocardial infarction can be defined as elevated cardiacbiomarkers together with ischemic symptoms or ECG-changes(ST-elevation or -depression, new left bundle branch block, or (newq-waves). Stroke can be defined as an acute onset of a focal neurologicaldeficit of presumed vascular origin lasting for 24 hours or more andfurther categorized as hemorrhagic or ischemic after imaging [3].
Vitamin $\mathrm{K}$ antagonists (VKA) were the only class of oral anticoagulants available to clinicians, but they have important limitations that can outweigh these advantages, such as the slow onset of action, a narrow therapeutic window and an unpredictable anticoagulant effect [4]. VKA-associated dietary precautions, monitoring, and dosing adjustment to maintain the international normalized ratio (INR) within the therapeutic range, and bridging therapy, are convenient for patients, expensive, and may result in inappropriate use of VKA therapy [5]. Several new oral anticoagulants with more stable pharmacokinetic and pharmacodynamic profiles have been licensed for clinical practice [6]. Rivaroxaban, apixaban (direct factor Xa inhibitor), and dabigatran (direct thrombin inhibitor) are the most extensively evaluated novel anticoagulant agents currently [7]. Monitoring of coagulation profiles is 
Ahmed et al. Cardiovascular System 2018,

not required, but patients should be followed up regularly to detect conditions that may lead to changes in the expected efficacy or safety [8], moreover, patients should be warned that reduced adherence or non-adherence to the treatment regimen could be fatal due to thromboembolic events.

\section{Methods}

\section{Study design}

This study is a randomized multicenter cross-sectional study.

\section{Study population}

This study population included 100 patients that come from CCU in multicenter presented with a recent ACS; patients were subdivided into two groups:

Group A: Fifty patients with ACS who received rivaroxaban $2.5 \mathrm{mg}$ once daily and were on dual antiplatelet therapy (aspirin and clopidogrel).

Group B: fifty patients with a recent ACS who received placebo (control group) and also were on dual antiplatelet therapy. This study included patients that had an ST-segment elevation myocardial infarction (STEMI), a non ST-segment elevation myocardial infarction (NSTEMI), or unstable angina. Key exclusion criteria included any additional antiplatelet therapy other than aspirin \&clopidogrel e.g. ticagrelor or prasugrel. planned $\mathrm{PCl}$, treatmentof vitamin $\mathrm{K}$ antagonist, recent stroke (within 12 months before randomization), Condition associated with increased risk of bleeding e.g. anemia(a hemoglobin level of less than $10 \mathrm{gs}$ per deciliter), thrombocytopenia (a platelet count of less than 90,000 per cubic millimeter) and a history of severe bleeding (clinically significant gastrointestinal bleeding within 12 months before randomization, and previous intracranial hemorrhage), renal impairment (a creatinine clearance of less than $30 \mathrm{ml}$ per minute at screening).

\section{Baseline evaluation}

-Full history taking and clinical examination.

- 12 lead ECG on admission and whenever indicated.

- Routine laboratory investigation including, random blood sugar, lipid profile, kidney function tests (urea and creatinine), liver enzymes (SGPT \&SGOT), cardiac enzymes (troponin \&CKMB), CBC, PT, PTT, INR.

-Transthoracic echocardiography.

\section{Study endpoints}

Primary endpoint: six months adverse events including a composite of death from cardiovascular events, myocardial infarction, and stroke.

Secondary endpoint: death from cardiovascular events, myocardial infarction, or stroke with assessing the safety (risk of bleeding) at six months.

\section{Statistical analysis}

The collected data were tabulated and analyzed using (Statistical Package for Social Studies) SPSS version 21. Categorical variables were presented as number and percentages while continuous variables were expressed as a mean \pm standard deviation. Chi-square tests (X2) " $\mathrm{Z}$ " test and student " $\mathrm{t}$ " tests were used. The accepted level of significance of this work was stated $\mathrm{P}<0.05$.

\section{Results}

There was no significant difference between the two groups regarding age as the mean age of patients in group $A$ was $63.56 \pm 5.15$ years and the mean age of patients in group $B$ was $62.92 \pm 5.99$ years ( $p$-value $=0.568$ ), also there was no significant difference between two groups regarding sex distribution as $36 \%$ of patients in group $A$ was males and $64 \%$ of the same group were females and group B included males constituting $34 \%$ of the group and females representing $66 \%$ of the group ( $p$-value $=0.834$ ). Body mass index (BMI) showed no significant difference between two groups as the mean BMI of patients in group $A$ was $26.22 \pm 1.82$ and $25.86 \pm 1.82$ among patients in group $B(p$-value $=0.325$ ) (Table 1), (Figures 1-3).

Table 1. Comparison of demographic data among studied groups.

\begin{tabular}{llllll}
\hline & & Group A & Group B & Test & p-value \\
\hline Age & Range & $50-70$ & $48-70$ & T: 0.328 & 0.568 \\
& Mean \pm S. D & $63.56 \pm 5.15$ & $62.92 \pm 5.99$ & & \\
\hline \multirow{2}{*}{ BMI } & Range & $23-29$ & $22-29$ & T: 0.978 & 0.325 \\
& Mean \pm S. D & $26.22 \pm 1.82$ & $25.86 \pm 1.82$ & & \\
\hline Sex & Male (\%) & $18(36 \%)$ & $17(34 \%)$ & $\mathrm{X}^{2}: 0.044$ & 0.834 \\
& Female (\%) & $32(64 \%)$ & $33(66 \%)$ & & \\
\hline
\end{tabular}

$\chi 2$ : Chi-square test, t: Student t-test

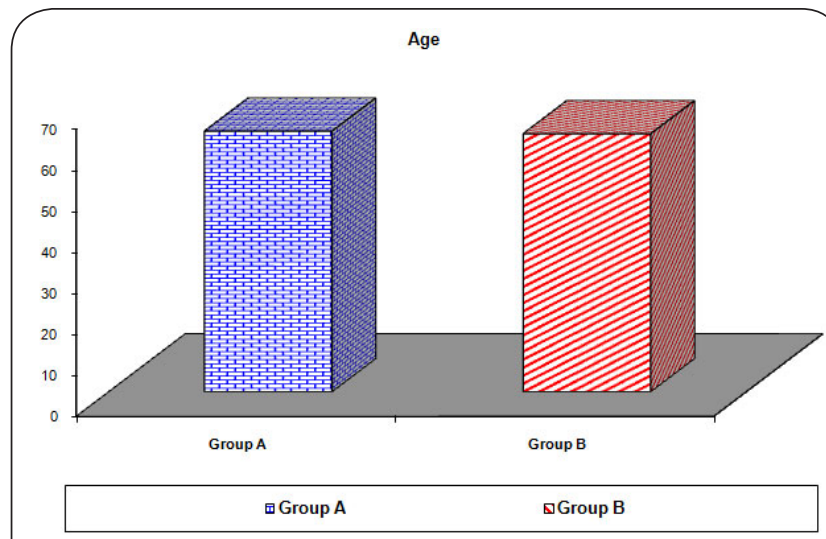

Figure 1. Comparison between two groups with regard to age.

Comparison between two groups regarding risk factors revealed no significant difference, as hypertension was in $60 \%$ of patients in group $A$ and $44 \%$ of patients in group B ( $p$-value $=0.109$ ), also diabetes mellitus was in $62 \%$ of patients in group $A$ and $48 \%$ of patients in group $B$ ( $p$-value $=0.159$ ), smoking was in $40 \%$ of patients in group $A$ and $46 \%$ of pa- 


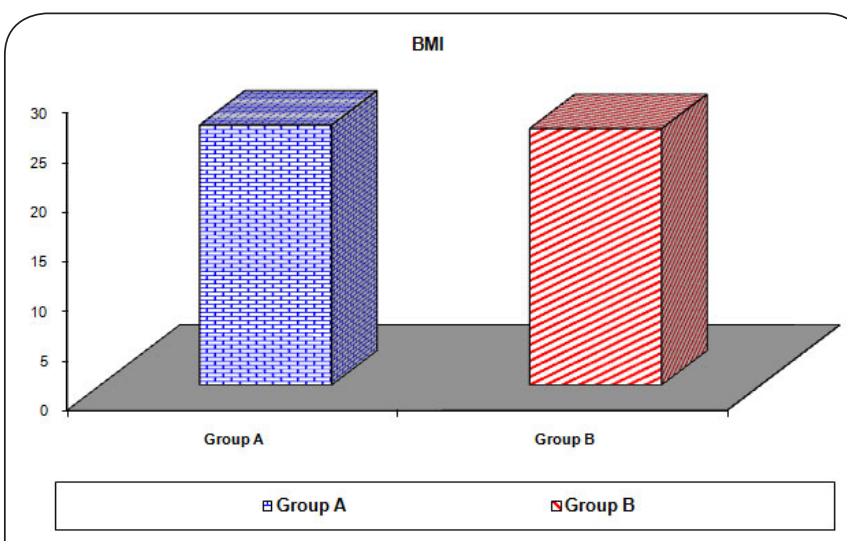

Figure 2. Comparison between two groups with regard to sex.

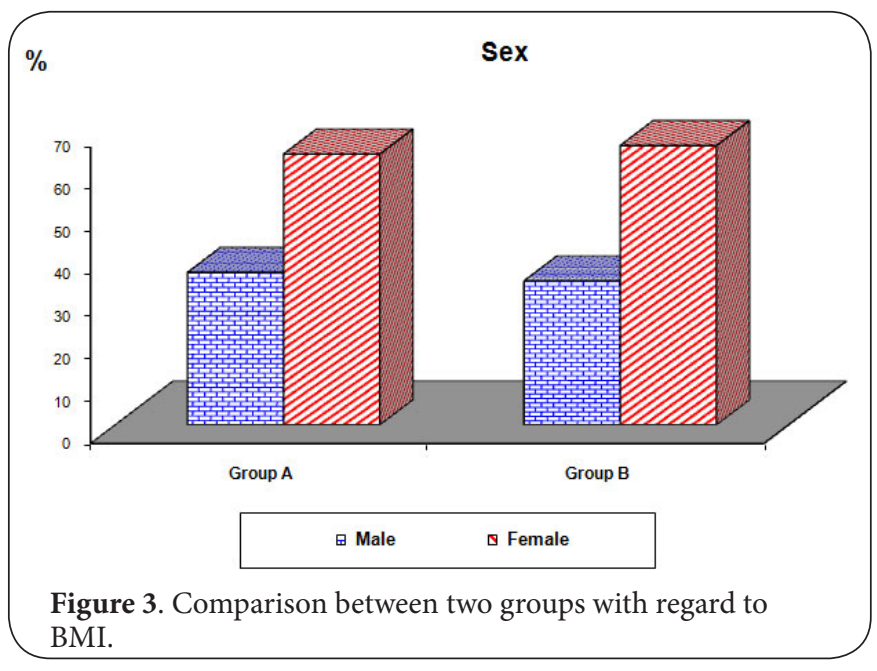

tients in group $B(p$-value $=0.545)$, and dyslipidemia was in $58 \%$ of patients in group A versus $52 \%$ of patients in group $B$ ( $p$-value=0.546) (Table2), (Figure 4).

Regarding type of acute coronary syndrome showed no significant difference as NSTEMI was present in 20\% in group $A$ and $24 \%$ in the group B, while STEMI was present in $60 \%$ in group $A$ and $56 \%$ in group $B$ and unstable angina was present in 20\% in group A and 20\% in the group B (P-value) (Table 3), (Figure 5).

As regards primary efficacy endpoint of death from cardiovascular causes, myocardial infarction and stroke, six months follow up revealed a highly significant difference, as it was present in $4 \%$ of patients in group $A$ while it was present in $22 \%$ in group $B$ (P-value0.007). Death from cardiovascular events represents $0 \%$ in group $A$ and $8 \%$ in group $B$ ( $p$-value), Mlrepresents $2 \%$ in group $A$ and $12 \%$ in group $B$ ( $p$-value), strokerepresent $2 \%$ in group $A$ and $2 \%$ in group $B$ ( $p$-value) (Table 4), (Figure 5).

Regarding major bleeding and fatal bleeding, six months follow up data revealed that there was no major or fatal bleeding had been recorded in both groups. Minor bleeding
Table 2. Comparison of risk factors among studied groups.

\begin{tabular}{lccllll}
\hline & & & Group A & Group B & X $^{2}$ & P-value \\
\hline HTN & +ve & N & 30 & 22 & 2.562 & 0.109 \\
& & $\%$ & $60.0 \%$ & $44.0 \%$ & & \\
& -ve & N & 20 & 28 & & \\
& & $\%$ & $40.0 \%$ & $56.0 \%$ & & \\
\hline DM & +ve & N & 31 & 24 & 1.980 & 0.159 \\
& & $\%$ & $62.0 \%$ & $48.0 \%$ & & \\
& -ve & N & 19 & 26 & & \\
& & $\%$ & $38.0 \%$ & $52.0 \%$ & & \\
\hline IHD & +ve & $\mathrm{N}$ & 18 & 13 & 1.169 & 0.280 \\
& & $\%$ & $36.0 \%$ & $26.0 \%$ & & \\
& -ve & $\mathrm{N}$ & 32 & 37 & & \\
& & $\%$ & $64.0 \%$ & $74.0 \%$ & & \\
\hline Smoking & +ve & $\mathrm{N}$ & 20 & 23 & 0.367 & 0.545 \\
& & $\%$ & $40.0 \%$ & $46.0 \%$ & & \\
& -ve & $\mathrm{N}$ & 30 & 27 & & \\
& & $\%$ & $60.0 \%$ & $54.0 \%$ & & \\
\hline Hyperlipidemia & +ve & $\mathrm{N}$ & 29 & 26 & 0.364 & 0.546 \\
& & $\%$ & $58.0 \%$ & $52.0 \%$ & & \\
& -ve & $\mathrm{N}$ & 21 & 24 & & \\
& & $\%$ & $42.0 \%$ & $48.0 \%$ & & \\
\hline
\end{tabular}

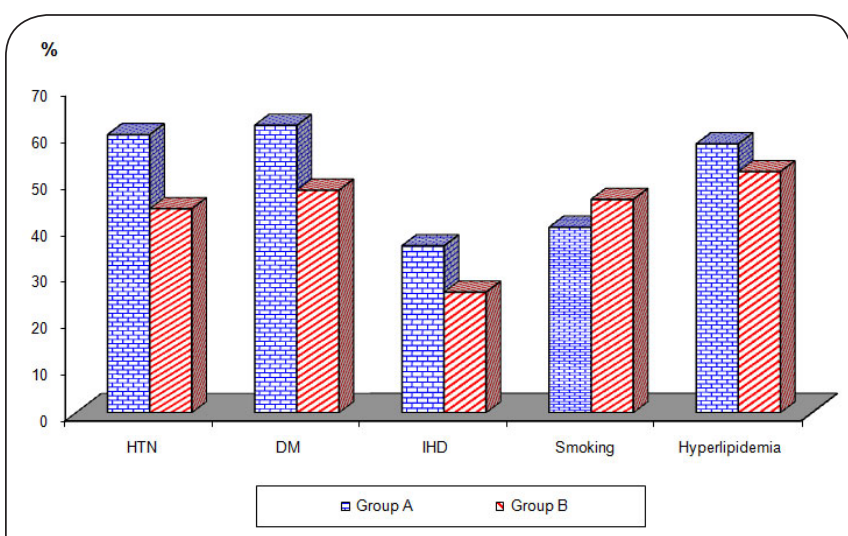

Figure 4. Shows a comparison between two groups with regard to risk factors.

Table 3. Comparison of risk factors among studied groups.

\begin{tabular}{lclllll}
\hline & & & Group A & Group B & $\mathbf{X}^{\mathbf{2}}$ & P-value \\
\hline Diagnosis & NST & N & 10 & 12 & 0.251 & 0.882 \\
& & $\%$ & $20.0 \%$ & $24.0 \%$ & & \\
& ST & N & 30 & 28 & & \\
& & $\%$ & $60.0 \%$ & $56.0 \%$ & & \\
& UA & N & 10 & 10 & & \\
& & $\%$ & $20.0 \%$ & $20.0 \%$ & & \\
\hline
\end{tabular}

was observed in $12 \%$ of patients in group A, while it was $2 \%$ in group $B$ ( $p$-value 0.049), and bleeding required medical attention occurred also in 12\%(6 patients) in group $A$ versus $2 \%(1$ patient) in group B (p-value 0.049) (Table 5), (Figure 7). 


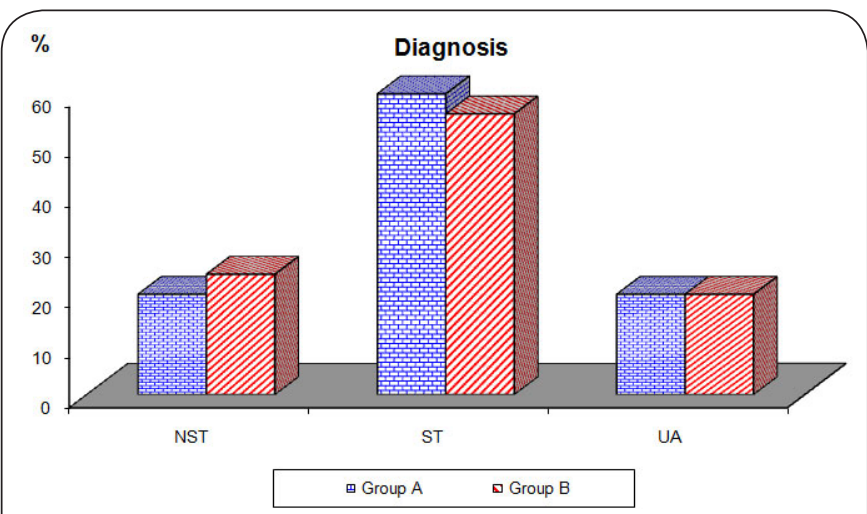

Figure 5. Shows a comparison between two groups with regard to the type of ACS.

Table 4. Comparison of MACE among studied groups.

\begin{tabular}{lllllll}
\hline & & & Group A & Group B & $\mathbf{X}^{2}$ & P-value \\
\hline Primary end point & + ve & $\mathrm{N}$ & 2 & 11 & 7.162 & $0.007^{*}$ \\
& & $\%$ & $4.0 \%$ & $22.0 \%$ & & \\
& -ve & $\mathrm{N}$ & 48 & 39 & & \\
& & $\%$ & $96.0 \%$ & $78.0 \%$ & & \\
\hline Death. CVD & +ve & $\mathrm{N}$ & 0 & 4 & 4.173 & $0.041^{*}$ \\
& & $\%$ & $0 \%$ & $8.0 \%$ & & \\
& -ve & $\mathrm{N}$ & 50 & 46 & & \\
& & $\%$ & $100.0 \%$ & $92.0 \%$ & & \\
\hline MI & +ve & $\mathrm{N}$ & 1 & 6 & 3.844 & $0.049^{*}$ \\
& & $\%$ & $2.0 \%$ & $12.0 \%$ & & \\
& -ve & $\mathrm{N}$ & 49 & 44 & & \\
& $\%$ & $98.0 \%$ & $88.0 \%$ & & \\
\hline Stroke & +ve & $\mathbf{N}$ & 1 & 1 & 0.0 & 1.0 \\
& & $\%$ & $2.0 \%$ & $2.0 \%$ & & \\
& -ve & $\mathbf{N}$ & 49 & 49 & & \\
& & $\%$ & $98.0 \%$ & $98.0 \%$ & & \\
\hline
\end{tabular}

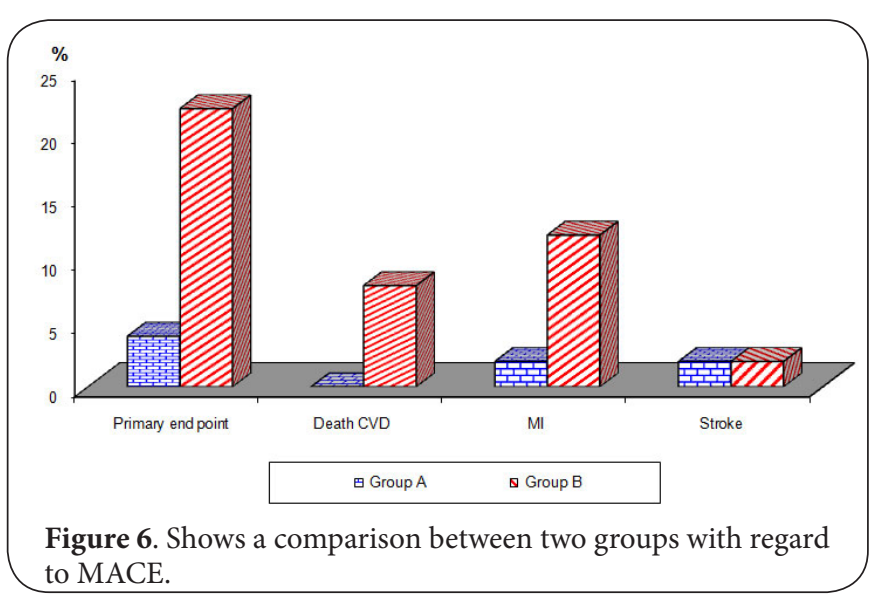

\section{Discussion}

Coronary heart disease is responsible for more than half of all cardiovascular events in individuals less than 75 years of
Table 5. Comparison of bleeding among studied groups.

\begin{tabular}{lccllll}
\hline & & & Group A & Group B & $\mathbf{X}^{2}$ & P-value \\
\hline Major bleeding & + ve & $\mathrm{N}$ & 0 & 0 & - & - \\
& & $\%$ & $.0 \%$ & $.0 \%$ & & \\
& -ve & $\mathrm{N}$ & 50 & 50 & & \\
& & $\%$ & $100.0 \%$ & $100.0 \%$ & & \\
\hline Minor bleeding & $+\mathrm{ve}$ & $\mathrm{N}$ & 6 & 1 & & $0.049^{*}$ \\
& & $\%$ & $12.0 \%$ & $2 \%$ & & \\
& -ve & $\mathrm{N}$ & 44 & 49 & 3.844 & \\
& & $\%$ & $88.0 \%$ & $98.0 \%$ & & \\
\hline Bleeding attention & $+\mathrm{ve}$ & $\mathrm{N}$ & 6 & 1 & 3.844 & $0.049^{*}$ \\
& & $\%$ & $12.0 \%$ & $2.0 \%$ & & \\
& -ve & $\mathrm{N}$ & 44 & 49 & & \\
& & $\%$ & $88.0 \%$ & $98.0 \%$ & & - \\
\hline Fetal bleeding & $+\mathrm{ve}$ & $\mathrm{N}$ & 0 & 0 & - & - \\
& & $\%$ & $.0 \%$ & $.0 \%$ & & \\
& -ve & $\mathrm{N}$ & 50 & 50 & & \\
& & $\%$ & $100.0 \%$ & $100.0 \%$ & & \\
\hline
\end{tabular}

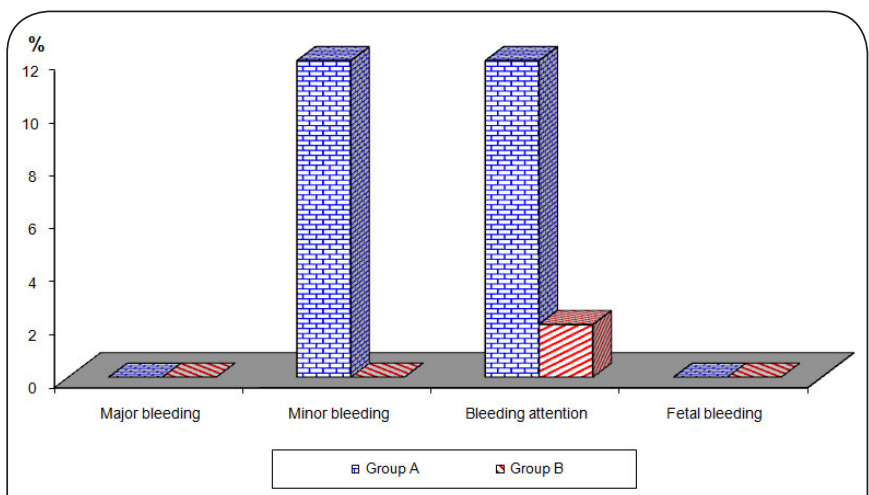

Figure 7. Shows a comparison between two groups with regard to bleeding.

age. ACS refers to a group of conditions due to decreased blood flow in the coronary arteries such that part of the heart muscle is unable to function properly or dies [9]. The most common symptom is chest pain, often radiating to the left arm or angle of the jaw, pressure-like in character, and associated with nausea and sweating. The acute coronary syndrome usually occurs as a result of one of the problems: (STEMI, 30\%), (NSTEMI, 25\%) or unstable angina (38\%) [10].

Platelets play a major pathogenic role in thrombus formation. Clopidogrel treatment in combination with aspirin can prevent recurrent ischemic events after ACS [11]. Despite treatment with dual-antiplatelet therapy, patients with stabilized ACS have an $\approx 9 \%$ to $11 \%$ risk of suffering a recurrent adverse cardiovascular event within 1 year $[12,13]$.

Rivaroxaban, another new factor $\mathrm{Xa}$, and Ila inhibitors have been evaluated in patients after ACS. The phase 2 programs, which evaluated rivaroxaban, apixaban, dabigatran, and darexaban, all showed a dose-dependent increase in bleeding [14]. Studies have shown that thrombin levels stay elevated for 
months after an ACS eventwith a persistently elevated risk of adverse events despite antiplatelet therapy, so it is appealing to consider adding anticoagulation to the long-term care of patients with stabilized ACS to lower thrombin levels and improve outcomes [15].

In this study, we evaluated the safety and indicators of efficacy of the novel oral anticoagulant rivaroxaban $(2.5 \mathrm{mg}$ once daily) after ACS in patients who remain at risk of recurrent ischemic events, despite contemporary treatment, including aspirin and clopidogrel.

As regard age, there was no significant difference between two groups, as the mean age of patients in group A was 63.56 years and the mean age of patients in group B was 62.925 .99 years ( $p$-value0.568). Alhabiba and his colleagues in 2011 found that the average age of ACS presentation 5812.9 years in the study included 5055 patients [16].

As regard sex, there was no significant difference between two groups as $36 \%$ of patients in group A were males while $34 \%$ of group B were males ( $p$-value0.834) (Table 1). Data from the Framingham Heart Study suggest that a harmful cardiovascular risk profile may be more cause than a consequence of age at menopause [17].

As regard risk factors, there was no significant difference between two groups, regarding diabetes mellitus, as $62 \%$ of patients in group A were diabetics while $48 \%$ of group B were diabetics ( $p$-value $=$ ). People with diabetes are at elevated risk for a number of serious health problems including cardiovascular disease and it is the most common complication associated with diabetes [18], Ahmed and his colleagues found in study aimed to assess the frequency of diabetes mellitus in patients with acute coronary syndrome 79 (31.6\%) patients out of 250 patients of ACS who had diabetes [19]. Regarding smoking, $40 \%$ of patients in group A were smoker while $46 \%$ of group B was a smoker and regarding hypertension $30 \%$ of group A were hypertensive and $22 \%$ of group B were hypertensive ( $p$-value $=0.109$ ). Aygul and his associates stated that hypertension and smoking are the major and potentially modifiable traditional risk factors that substantially increase the risk of developing Coronary heart disease [20].

In our study, regarding primary efficacy end point (death from cardiovascular causes, myocardial infarction, and stroke) in patients with a recent acute coronary syndrome six months follow up revealed that rivaroxaban significantly reduced the primary efficacy end point ( 2 patients in group A versus 11 patients in group $B, p$-value), and these findings are agree withboth ATLAS-ACS 2-TIMI-51 trialin 2012with two doses of $2.5 \mathrm{mg}$ rivaroxaban, and ATLAS-ACS-TIMI-46 trial with two doses of $5 \mathrm{mg}$ rivaroxabanwhich showed that, treatmentwhen

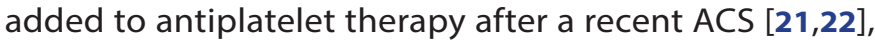
reduced primary efficacy end point, and disagree with APPRAISE- 2 and RUBY- 1 trials which showed non-significant reduction in the primary end point $[23,24]$.

As regard death from cardiovascular events and myocardial (re) infarction, there was a highly statistically significant difference between the two groups, as death from cardiovascular events was in $0 \%$ patients of group $A$, while it was in $8 \%$ (4 patients) of group B ( $p$-value $=0.041)$, and Ml was in $2 \%$ (1 patient) of group $A$, while it was $12 \%$ (6 patients) of group $B$ ( $p$-value $=0.049$ ), and this agrees with ATLAS ACS2TIMI-51 and ATLAS ACS-TIMI-46, APPRAISE-1, and REDEEM trials which showed significant reduction in the rate of death from cardiovascular events and MI with using NOACs after ACS $[\mathbf{2 1}, \mathbf{2 2}, \mathbf{2 6}, \mathbf{2 7}]$, and disagree with APPRAISE-2 and RUBY-1 trials which showed non-significant reduction in the rate of death from cardiovascular events and MI [23,24].

As regard stroke prevention after ACS, there was no statistically significant difference between the two groups, as the incidence of stroke was in $2 \%$ of patients in group A (1 patient), and it was the same in group $B$, and this agrees with ATLAS ACS 2-TIMI-51 and APPRAISE-2 trials which revealed that rivaroxaban $(2.5 \mathrm{mg}$ bid) andapixaban $(5 \mathrm{mg}$ bid) did not significantly reduce the incidence of stroke after ACS respectively $[\mathbf{2 1 , 2 3 ]}$.

Regarding major bleeding, six months follow up revealed that there was no major bleeding had been recorded in both groups, and these findings disagreed with ATLAS ACS 2-TIMI51, ATLAS ACS-TIMI-46, APPRAISE-1, RE-DEEM, APPRAISE-2 and RUBY-1 trials which showed significant increase in the rate of major bleeding in patients who received NOAC, this difference between our study and the previous studies as regard major bleeding may be due to small sample size in our study and also lower dose of rivaroxaban $(2.5 \mathrm{mg}$ once

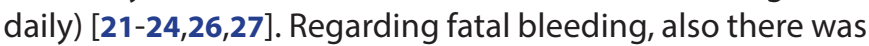
no fatal bleeding in both groups, and these findings agreed with ATLAS ACS 2-TIMI-51, ATLAS ACS-TIMI-46, APPRAISE-1 trials, which showed a non-significant difference between the two groups $[21,22,25,26]$.

As regard minor bleeding and bleeding required medical attention, there was a statistically significant difference between the two groups, as minor bleeding was in $12 \%$ of patients in group $A$, while it was in $2 \%$ of group B ( $p$-value 0.049 ), and bleeding required medical attention also was in $12 \%$ of patients in group A (6patient), while it was in $2 \%$ of group B (1 patients) ( $p$-value 0.049), and this agrees with ATLAS ACS 2-TIMI 51 trial, ATLAS ACS-TIMI 46 trial, APPRAISE-2, RE-DEEM study and RUBY-1 trial which showed significant increase in the rate of minor bleeding and bleeding required medical attention with NOACs after acute coronary syndrome [21-24,27].

\section{Study Limitations}

-Small sample size.

-Short follow up.

-The incidence of adverse events (major and minor bleeding). -Lack of randomization.

\section{Conclusion}

In patients with a recent acute coronary syndrome, rivar- 
Ahmed et al. Cardiovascular System 2018,

oxaban reduces the risk of the composite endpoint of death from cardiovascular causes, myocardial infarction, and stroke. Regarding safety, rivaroxaban increases the risk of minor bleeding but not the risk of major or fatal bleeding.

\section{List of abbreviations}

ACS: Acute coronary syndrome

MACE: Major Adverse Cardiovascular Events

NOAC: Novel oral anticoagulant

NSTEMI:Non St Segment Elevation Myocardial Infarction.

PCl: Percutaneous Coronary Intervention

Competing interests

The authors declare that they have no competing interests.

Authors' contributions

\begin{tabular}{|l|c|c|c|c|}
\hline Authors' contributions & HQ & AR & MS & KA \\
\hline Research concept and design & $\checkmark$ & $\checkmark$ & $\checkmark$ & $\checkmark$ \\
\hline Collection and/or assembly of data & $\checkmark$ & $\checkmark$ & $\checkmark$ & $\checkmark$ \\
\hline Data analysis and interpretation & $\checkmark$ & $\checkmark$ & $\checkmark$ & $\checkmark$ \\
\hline Writing the article & $\checkmark$ & $\checkmark$ & $\checkmark$ & $\checkmark$ \\
\hline Critical revision of the article & $\checkmark$ & $\checkmark$ & $\checkmark$ & $\checkmark$ \\
\hline Final approval of article & $\checkmark$ & $\checkmark$ & $\checkmark$ & $\checkmark$ \\
\hline Statistical analysis & $\checkmark$ & $\checkmark$ & $\checkmark$ & $\checkmark$ \\
\hline
\end{tabular}

Publication history

Editor: Shiwei Duan, Ningbo University, China.

Received: 07-April-2018 Final Revised: 06-Jun-2018

Accepted: 21-Jul-2018 Published: 17-Aug-2018

\section{References}

1. Ineid $H$, Anderson JL, Wright RS, Adams $C D$, Bridges $C R$, Casey $D E$, Jr., Ettinger SM, Fesmire FM, Ganiats TG, Lincoff AM, Peterson ED, Philippides GJ, Theroux P, Wenger NK and Zidar JP. 2012 ACCF/AHA focused update of the guideline for the management of patients with unstable angina/non-ST-elevation myocardial infarction (updating the 2007 guideline and replacing the $\mathbf{2 0 1 1}$ focused update): a report of the American College of Cardiology Foundation/American Heart Association Task Force on Practice Guidelines. J Am Coll Cardiol. 2012; 60:645-81. I Article I PubMed

2. O'Gara PT, Kushner FG and Ascheim DD. American College of Cardiology Foundation/American Heart Association Task Force on Practice Guidelines (2013). ACCF/AHA guideline for the treatment of STelevation myocardial infarction: the report of the American College of Cardiology Foundation/American Heart Association Task Force on Practice Guidelines. Circulation. 2013; 127:e362-e425. | Article

3. Oldgren J, Wallentin $\mathrm{L}$ and Alexender J. The New oral anticoagulant in addition to single or dual antiplatelet therapy after acute coronary syndrome. European Heart Journal. 2013; 34:1670-1680.

4. Ageno W, Gallus AS, Wittkowsky A, Crowther M, Hylek EM and Palareti G. American College of Chest Physicians Oral anticoagulant therapy: antithrombotic therapy and prevention of thrombosis, 9th ed. American College of Chest Physicians evidence-based clinical practice guidelines. Chest. 2012; 141:e44S-88S.

5. Friberg L, Rosenqvist M and Lip GY. Evaluation of risk stratification schemes for ischaemic stroke and bleeding in 182678 patients with atrial fibrillation: the Swedish Atrial Fibrillation cohort study. Eur Heart J. 2012; 33:1500-10. | Article | PubMed

6. Mismetti $P$ and Laporte $S$. New oral antithrombotics: a need for laboratory monitoring. For. J Thromb Haemost. 2010; 8:621-6. | Article I PubMed

7. Beyer-Westendorf J and Ageno W. Benefit-risk profile of non- vitamin $\mathrm{K}$ antagonist oral anticoagulants in the treatment of venous thromboembolism. Thromb Haemost. 2014; 16:113-128.

8. Heidbuchel $H$, Verhamme $P$, Alings $M$, Antz $M$, Hacke W, Oldgren J, Sinnaeve P, Camm AJ and Kirchhof P. European Heart Rhythm Association Practical Guide on the use of new oral anticoagulants in patients with non-valvular atrial fibrillation. Europace. 2013; 15:62551. | Article | PubMed

9. Amsterdam EA, Wenger NK, Brindis RG, Casey DE, Jr., Ganiats TG, Holmes $D R$, Jr., Jaffe AS, Jneid H, Kelly RF, Kontos MC, Levine GN, Liebson PR, Mukherjee D, Peterson ED, Sabatine MS, Smalling RW and Zieman SJ. 2014 AHA/ACC guideline for the management of patients with non-STelevation acute coronary syndromes: a report of the American College of Cardiology/American Heart Association Task Force on Practice Guidelines. Circulation. 2014; 130:e344-426. | Article | PubMed

10. Torres $\mathrm{M}$ and Moayedi S. Evaluation of the acutely dyspneic elderly patient. Clin Geriatr Med. 2007; 23:307-25. I Article I PubMed

11. Barilla F, Pulcinelli FM, Mangieri E, Torromeo C, Tanzilli G, Dominici T, Pellicano M, Paravati V, Acconcia MC and Gaudio C. Clopidogrel plus indobufen in acute coronary syndrome patients with hypersensitivity to aspirin undergoing percutaneous coronary intervention. Platelets. 2013; 24:183-8. | Article | PubMed

12. Wiviott SD, Braunwald E, McCabe CH, Montalescot G, Ruzyllo W, Gottlieb S, Neumann FJ, Ardissino D, De Servi S, Murphy SA, Riesmeyer J, Weerakkody G, Gibson CM and Antman EM. Prasugrel versus clopidogrel in patients with acute coronary syndromes. N Engl J Med. 2007; 357:2001-15. | Article | PubMed

13. Wallentin L, Becker RC, Budaj A, Cannon CP, Emanuelsson H, Held C, Horrow J, Husted S, James S, Katus H, Mahaffey KW, Scirica BM, Skene A, Steg PG, Storey RF, Harrington RA, Freij A and Thorsen M. Ticagrelor versus clopidogrel in patients with acute coronary syndromes. $N$ Engl $J$ Med. 2009; 361:1045-57. | Article I PubMed

14. Algren, Budaj $A$ and Granger $C B$ et al. Dabigatran versus placebo in patients with acute coronary syndrome on antiplatelet therapy: a randomized, double-blind, phase II trial. Eur Heart J. 2011.

15. Christersson C, Oldgren J, Bylock A, Wallentin L and Siegbahn A. Longterm treatment with ximelagatran, an oral direct thrombin inhibitor, persistently reduces the coagulation activity after a myocardial infarction. J Thromb Haemost. 2005; 3:2245-53. | Article | PubMed

16. Alhabiba KF, Heredia $A$ and Alfalfa $H$ et al. Baseline characteristics, management practices, and in-hospital outcomes in patients with acute coronary syndrome: Results of the Suadi project for assessment of coronary heart disease (SPACE).

17. Maas AHEM and Appelman YEA. Gender differences in coronary heart disease. Netherlands Heart Journal. 2010; 18:598-602.

18. Goff DC, Jr., Gerstein HC, Ginsberg HN, Cushman WC, Margolis KL, Byington RP, Buse JB, Genuth S, Probstfield JL and Simons-Morton DG. Prevention of cardiovascular disease in persons with type 2 diabetes mellitus: current knowledge and rationale for the Action to Control Cardiovascular Risk in Diabetes (ACCORD) trial. Am J Cardiol. 2007; 99:4i-20i. | Article | PubMed

19. Ahmed WH, Bittl JA and Braunwald E. Relation between clinical presentation and angiographic findings in unstable angina pectoris, and comparison with that in stable angina. Am J Cardiol. 1993; 72:544-50. | Article I PubMed

20. Aygul N, Ozdemir K, Duzenli MA and Aygul MU. The comparative effects of long-term carvedilol versus bisoprolol therapy on QT dispersion in patients with chronic heart failure. Cardiology. 2009; 112:168-73. | Article | PubMed

21. Mega JL, Braunwald E, Wiviott SD, Bassand JP, Bhatt DL, Bode C, Burton P, Cohen M, Cook-Bruns N, Fox KA, Goto S, Murphy SA, Plotnikov AN, Schneider D, Sun X, Verheugt FW and Gibson CM. Rivaroxaban in patients with a recent acute coronary syndrome. N Engl J Med. 2012; 366:9-19. | Article | PubMed

22. Mega JL, Braunwald E, Mohanavelu S, Burton P, Poulter R, Misselwitz $F$, Hricak V, Barnathan ES, Bordes P, Witkowski A, Markov V, Oppenheimer $L$ and Gibson CM. Rivaroxaban versus placebo in patients with acute coronary syndromes (ATLAS ACS-TIMI 46): a randomised, double-blind, 
Ahmed et al. Cardiovascular System 2018,

http://www.hoajonline.com/journals/pdf/2052-4358-6-2.pdf

phase II trial. Lancet. 2009; 374:29-38. | Article | PubMed

23. Alexander JH, Lopes RD, James S, Kilaru R, He Y, Mohan P, Bhatt DL, Goodman S, Verheugt FW, Flather M, Huber K, Liaw D, Husted SE, Lopez-Sendon J, De Caterina R, Jansky P, Darius $\mathrm{H}$ and Vinereanu $\mathrm{D}$ et al. Apixaban with antiplatelet therapy after acute coronary syndrome. $N$ Engl J Med. 2011; 365:699-708. | Article | PubMed

24. Steg PG, Mehta SR, Jukema JW, Lip GY, Gibson CM, Kovar F, Kala P, GarciaHernandez A, Renfurm RW and Granger CB. RUBY-1: a randomized, double-blind, placebo-controlled trial of the safety and tolerability of the novel oral factor Xa inhibitor darexaban (YM150) following acute coronary syndrome. Eur Heart J. 2011; 32:2541-54. | Article | PubMed Abstract | PubMed FullText

25. Carreras ET and Mega JL. Role of oral anticoagulants in patients after an acute coronary syndrome. Arterioscler Thromb Vasc Biol. 2015; 35:520-4. | Article | PubMed

26. Alexander JH, Becker RC, Bhatt DL, Cools F, Crea F, Dellborg M, Fox KA, Goodman SG, Harrington RA, Huber K, Husted S, Lewis BS, Lopez-Sendon J, Mohan P, Montalescot G, Ruda M, Ruzyllo W, Verheugt F and Wallentin L. Apixaban, an oral, direct, selective factor $\mathrm{Xa}$ inhibitor, in combination with antiplatelet therapy after acute coronary syndrome: results of the Apixaban for Prevention of Acute Ischemic and Safety Events (APPRAISE) trial. Circulation. 2009; 119:2877-85. | Article I PubMed

27. Oldgren J, Budaj A, Granger CB, Khder Y, Roberts J, Siegbahn A, Tijssen JG, Van de Werf $F$ and Wallentin L. Dabigatran vs. placebo in patients with acute coronary syndromes on dual antiplatelet therapy: a randomized, double-blind, phase II trial. Eur Heart J. 2011; 32:2781-9. | Article | PubMed

\section{Citation:}

QabiL HM, Ramzy AM, Abdelmoneum MS and Abd Elfattah KA. Assessing the efficacy of novel oral anticoagulants after acute coronary syndrome.

Cardio Vasc Syst. 2018; 6:2.

http://dx.doi.org/10.7243/2052-4358-6-2 